\title{
Cutaneous Melanoma by AJCC v6 Stage
}

National Cancer Institute

\section{Source}

National Cancer Institute. Cutaneous Melanoma by A/CC v6 Stage. NCI Thesaurus. Code C90514.

A term that refers to the staging of cutaneous melanoma, following the rules of the TNM AJCC v6 classification system. 